\title{
AN ASSESSMENT OF ANGIOGENESIS IN FIBROCYSTIC BREAST DISEASE AND INVASIVE BREAST CARCINOMA
}

\author{
Duraisamy Raman', Sudha Boj2, Dhanalakshmi Arumugam³, Lalitha Chidambaram ${ }^{4}$ \\ ${ }^{1}$ Assistant Professor, Department of Pathology, Government Mohan Kumaramangalam Medical College, Salem. \\ ${ }^{2}$ Senior Assistant Professor, Department of Pathology, Coimbatore Medical College. \\ ${ }^{3}$ Associate Professor, Department of Pathology, Coimbatore Medical College. \\ ${ }^{4}$ Professor and HOD, Department of Pathology, Coimbatore Medical College.
}

\section{ABSTRACT}

\section{BACKGROUND}

Fibrocystic disease (FCD) of breast is one of the most common benign condition of the breast, and breast cancer is the second most common cancer in women. Ductal hyperplasia is a frequent constituent of fibrocystic change. Moderate to florid hyperplasia is at slightly increased risk of breast carcinoma. In recent years, evidences suggest that quantification of angiogenesis by immune staining for endothelial cell markers may be a useful prognostic predictor.

\section{MATERIALS AND METHODS}

30 cases of FCD of breast and 30 cases of invasive breast carcinoma were immunohistochemically stained for CD34 and microvessel density was assessed in 3 highly vascularised spots and the average was taken.

\section{RESULTS}

In present study, the association between ductal epithelial hyperplasia in FCD and grade of microvessel density was statistically significant ( $p$ value< 0.05 ). The correlation between histological grade of IDC- NOS Type and grade of microvessel density was statistically significant ( $\mathrm{p}$ value $<0.05$ ).

\section{CONCLUSION}

The extent of angiogenesis in FCD with hyperplasia and invasive ductal carcinoma is an important prognostic factor.

\section{KEYWORDS}

Angiogenesis, Microvessel Density, Fibrocystic Disease of Breast, Invasive Ductal Carcinoma.

HOW TO CITE THIS ARTICLE: Raman D, Boj S, Arumugam D, et al. An assessment of angiogenesis in fibrocystic breast disease and invasive breast carcinoma. J. Evolution Med. Dent. Sci. 2017;6(78):5553-5556, DOI: 10.14260/jemds/2017/1206

\begin{abstract}
BACKGROUND
Most women have fibrocystic change, ${ }^{1}$ though in many it is mild and passes undetected. Clinically evident fibrocystic changes are common in women between 35 and 50 years old. ${ }^{2}$ Its incidence is significantly increased by nulliparity, late age of first birth, and late menopause, factors also associated with increased risk for breast carcinoma. Ductal and lobular hyperplasia, cyst formation, adenosis and fibrosis are major morphologic changes of fibrocystic breast disease. Ductal Epithelial hyperplasia, a significant risk factor for breast carcinoma, is a frequent constituent of fibrocystic disease of breast. $^{3}$
\end{abstract}

Breast cancer is the most common non-skin malignancy in women and is the second leading cause of cancer related deaths in females all over the world. ${ }^{4}$ It has doubled in India over the last two decades.

Angiogenesis is the physiological process through which new blood vessels form from pre-existing vessels. ${ }^{1}$ Angiogenesis is a normal and vital process in growth and

'Financial or Other Competing Interest': None.

Submission 21-08-2017, Peer Review 17-09-2017,

Acceptance 23-09-2017, Published 28-09-2017.

Corresponding Author:

Dr. Sudha Boj,

\#42/1, $4^{\text {th }}$ Street, Sripathy Nagar

Nanjundapuram Road,

Coimbatore-641036, Tamilnadu.

E-mail: drsajithmenon@gmail.com

DOI: $10.14260 /$ jemds $/ 2017 / 1206$ development, as well as in wound healing and in the formation of granulation tissue. Tumour angiogenesis refers to growth of new blood vessels towards and within the tumour.

It facilitates tumour growth and metastasis.

Tumour angiogenesis is known to be regulated by growth factors secreted by host and tumour cells. Solid tumours require neovascularisation to grow beyond about $1 \mathrm{~mm}^{3}$.

Normally the extracellular matrix and basement membrane is degraded by matrix metalloproteinase. There are inhibitors of metalloproteinase which are present in tissue. The balance between metalloproteinase and their inhibitors are regulated normally.

With transformation from benign to malignant condition, and with increasing histologic grade the expression of matrix metalloproteinase is increased. There is increased level of matrix metalloproteinase in association with angiogenesis.

For initiation of new vessel formation, lack of oxygen is an important factor. There are two hypoxia inducible substances, which are HIF-1, and HIF-2.

In premalignant and malignant conditions of breast HIF-1 alpha level of expression is high. In well-differentiated tumours, the level of HIF-1 alpha is low.

Tumour angiogenesis assessed by measuring intratumoural microvessel density after immunostaining for endothelial cell markers, such as CD34, CD31, von Willebrand factor $(\mathrm{vWF})$ is an important prognostic factor in breast cancer. ${ }^{5}$

CD34 is a transmembrane glycoprotein expressed by endothelial cells and highlights vascular channel. ${ }^{6}$ Siitonen et 
$\mathrm{al}^{7}$ showed that anti-CD34 showed better staining performance than anti-CD31.

The present study analyses the expression of CD34 in fibrocystic disease of breast and breast cancer. The grade of microvessel density was assessed and correlated with presence of epithelial hyperplasia in fibrocystic disease of breast and with varying grades of invasive ductal carcinoma.

\section{MATERIALS AND METHODS}

\section{Study Design}

Descriptive study

\section{Inclusion Criteria}

All breast specimens including mastectomy and breast biopsy specimen with features of fibrocystic disease that were received in the Department of Pathology, Coimbatore Medical College, Coimbatore over a period of 1 year.

\section{Exclusion Criteria}

1) Patient on chemotherapy and radiotherapy.

2) Male breast specimens.

The tissues were received in $10 \%$ formalin. The tissues were processed routinely, paraffin sections were cut at 4 to 5 $\mu \mathrm{m}$ thickness and stained with haematoxylin and eosin stain and then immunohistochemical study for CD34 was done.

Haematoxylin and eosin stained sections were reviewed and histomorphological grading was done by using ScarffBloom-Richardson (SBR) grading system which was based on parameters including percentage of Tubular pattern, Nuclear pleomorphism and mitotic activity.

The evaluation of microvessel density (MVD) using CD34 staining was performed by capillary counting in the three most highly vascularised areas (hot spots) initially selected under $40 \mathrm{x}$ field. Then a $400 \mathrm{x}$ field was used to count microvessels in each of these areas. The average microvessel density of three fields at 400x magnification was calculated. Single or clusters of endothelial cells, with or without lumen were considered to be individual vessels. Large vessel with muscular wall, microvessel in necrotic area and periphery of the tumour field were excluded.

The Scoring of Microvessel Density was done as follows-

- Mild MVD - 4-10 capillary.

- Moderate MVD - 11 -20 capillary.

- Severe MVD - 21-28 capillary.

The MVD grade was compared to presence of epithelial hyperplasia in fibrocystic disease of breast and histological grade of breast carcinoma.

\section{Statistical Analysis}

The results were tabulated and analysed for statistical significance using chi-square test. A 'p' value of $<0.05$ was considered to be statistically significant.

\section{RESULTS}

Total of 30 cases of fibrocystic disease of breast and 30 cases of invasive breast carcinoma were studied and the following observations were obtained.

Majority $(50 \%)$ of the cases of fibrocystic disease of breast were in the age group between 20-39 years. Most common morphological changes of fibrocystic disease were usual ductal epithelial hyperplasia (seen in $67 \%$ of cases), followed by cyst formation (47\%) and fibrosis (33\%).

$40 \%$ of fibrocystic breast disease cases without hyperplasia showed mild grade microvessel density score (MVD Score), while 20\% showed severe grade MVD score. Whereas $45 \%$ of fibrocystic breast disease cases with hyperplasia showed severe grade MVD score. Using chi square test the association between ductal epithelial hyperplasia and grade of microvessel density was found to be statistically significant. $(\mathrm{p}<0.05)$

Majority $(40 \%)$ of invasive ductal carcinoma -NOS type cases belonged to 50-59 years of age group. Most of the invasive ductal carcinoma -NOS type were grade II tumours (46.6\%), followed by grade III tumours (33.4\%). Severe grade microvessel density was seen in $33 \%$ of grade I cases $50 \%$ of grade II cases and $70 \%$ of grade III cases. The correlation between histological grade of invasive ductal carcinoma-NOS type and grade of microvessel density was statistically significant $(\mathrm{p}<0.05)$.

\begin{tabular}{|c|c|c|}
\hline AGE(Years) & NUMBER & PERCENTAGE (\%) \\
\hline $20-39$ & 15 & $50 \%$ \\
\hline $40-49$ & 12 & $40 \%$ \\
\hline $50-59$ & 3 & $10 \%$ \\
\hline$\geq 60$ & 0 & $0 \%$ \\
\hline
\end{tabular}

Table 1. Distribution of Fibrocystic Breast Disease Cases According to Different Age Groups

\begin{tabular}{|l|c|l|l|c|}
\hline \multicolumn{1}{|c|}{ MORPHOLOGY } & \multicolumn{4}{|c|}{ MVD SCORE (Grade) } \\
\cline { 2 - 5 } & MILD & MODERATE & SEVERE & Total \\
\hline $\begin{array}{l}\text { Epithelial hyperplasia } \\
\text { Absent }\end{array}$ & $4(13.3 \%)$ & $4(13.3 \%)$ & $2(6.6 \%)$ & $10(33.3 \%)$ \\
\hline $\begin{array}{l}\text { Epithelial hyperplasia } \\
\text { Present }\end{array}$ & $5(16.6 \%)$ & $6(20 \%)$ & $9(30 \%)$ & $20(66.7 \%)$ \\
\hline Total & & & & \\
\hline
\end{tabular}

Table 2. Correlation of Epithelial Hyperplasia with Microvessel Density Score (Grade)

Chi-square test $=0.001(\mathrm{p}<0.05)$.

In this study, severe grade of Microvessel density was associated with epithelial hyperplasia. This is statistically significant.

\begin{tabular}{|c|c|c|}
\hline $\begin{array}{c}\text { HISTOLOGICAL } \\
\text { GRADE }\end{array}$ & NUMBER & PERCENTAGE (\%) \\
\hline GRADE I & 6 & $20 \%$ \\
\hline GRADE II & 14 & $46.6 \%$ \\
\hline GRADE III & 10 & $33.4 \%$ \\
& & \\
\hline
\end{tabular}

Table 3. Distribution of Invasive Ductal

Carcinoma- Number, Type, Cases According To Histological Grade 
Majority of Invasive ductal carcinoma cases were histological grade II.

\begin{tabular}{|c|c|c|c|c|}
\hline \multirow{2}{*}{$\begin{array}{c}\text { Histological } \\
\text { Grade }\end{array}$} & \multicolumn{3}{|c|}{ MVD Grade } & \multirow{2}{*}{ Total } \\
\cline { 2 - 4 } & Mild & Moderate & Severe & \\
\hline Grade I & $1(3.4 \%)$ & $3(10 \%)$ & $2(6.6 \%)$ & $6(20 \%)$ \\
\hline Grade II & $2(6.6 \%)$ & $5(16.6 \%)$ & $7(23.4 \%)$ & $14(46.6 \%)$ \\
\hline Grade III & $1(3.4 \%)$ & $2(6.6 \%)$ & $7(23.4 \%)$ & $10(33.4 \%)$ \\
\hline Total & \multicolumn{4}{|c|}{$30(100 \%)$} \\
\hline \multicolumn{4}{|c|}{ Table 4. Correlation of Histological } \\
Grade with Microvessel Density Grade \\
\hline
\end{tabular}

Chi-square test $=0.002(\mathrm{p}<0.05)$.

Severe grade Microvessel density was seen in with grade III tumours and grade II tumours.

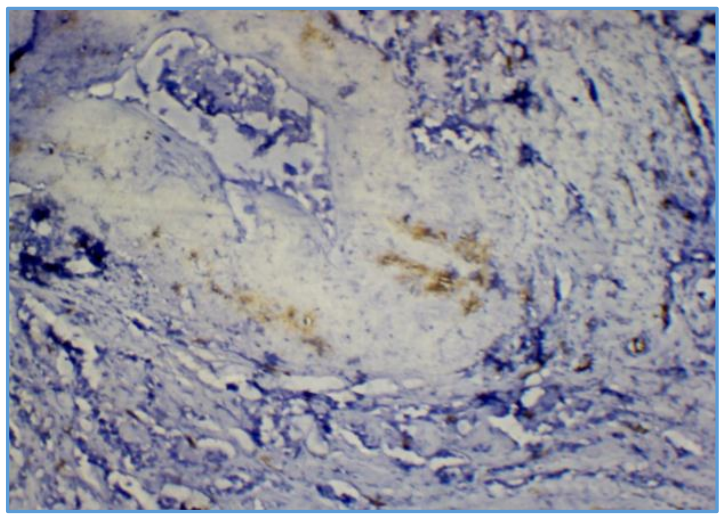

Figure 1. FCD - Microvessel Density CD34 Immunostain - Mild Degree (40X)

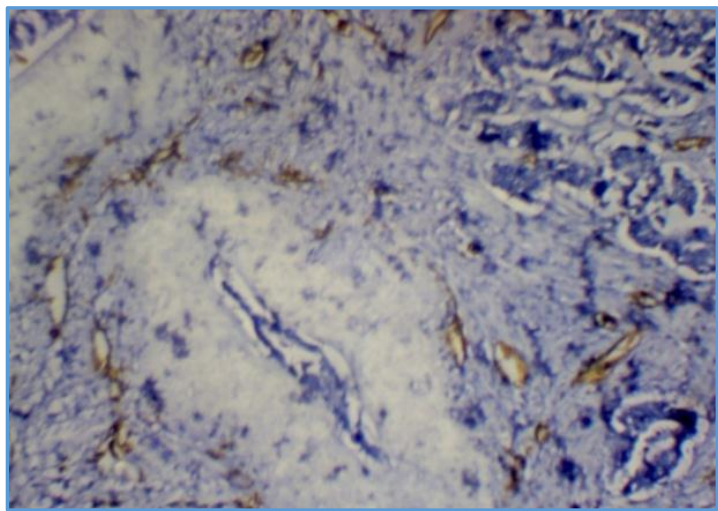

Figure 2. FCD - Microvessel Density CD34 Immunostain - Severe Degree (40X)

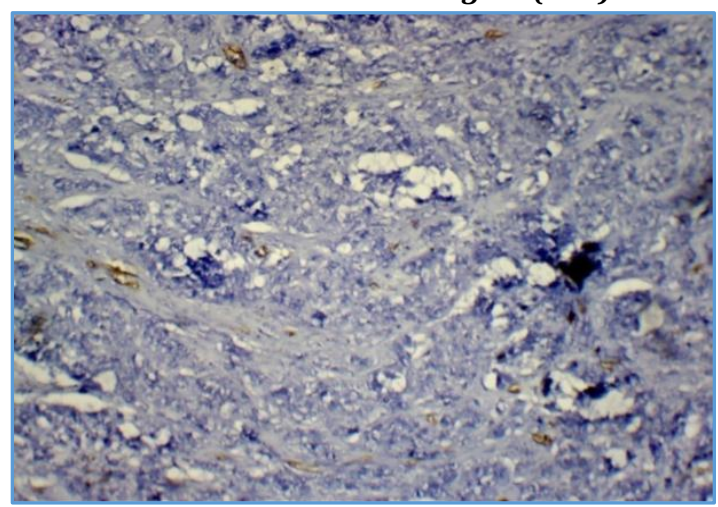

Figure 3. IDC-NOS Microvessel Density CD34 Immunostain - Mild Degree (10X)

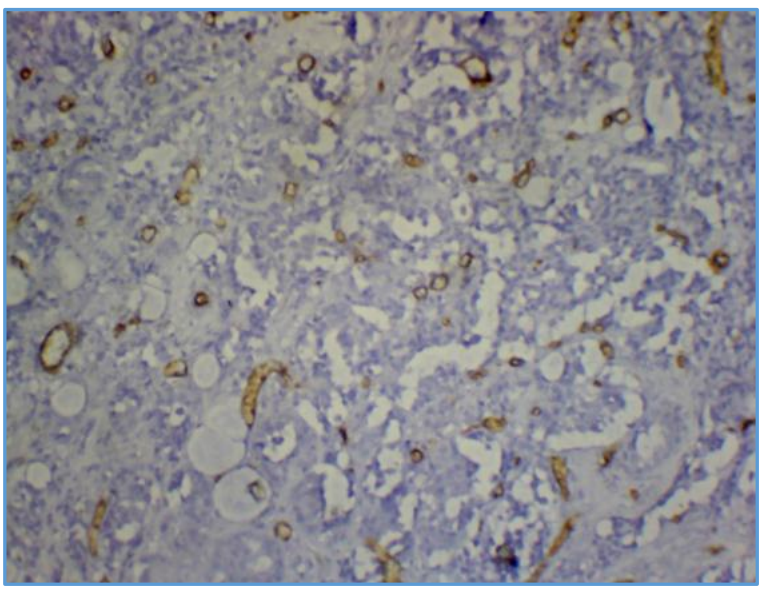

Figure 4. IDC-NOS Microvessel Density CD34 Immunostain - Severe Degree (10X)

\section{DISCUSSION}

Fibrocystic disease of breast is a benign condition of the breast due to exaggerated hormonally mediated response. The peak age of occurrence is between 30-50 years. 8,9

In the present study, the most common morphological changes of fibrocystic disease of breast were cyst formation and epithelial hyperplasia. Ductal epithelial hyperplasia poses less than twice the risk for malignant transformations. ${ }^{10,11,12}$

In present study, the grade of microvessel density correlates significantly with epithelial hyperplasia ( $p$ value $<$ 0.05). A study by Guinebretiere J.M. et al, ${ }^{13} \mathrm{~J}$ E Bluff. et al ${ }^{14}$ and Viacava $P$ et al ${ }^{15}$ showed similar results. Fregene et $\mathrm{al}^{16}$ in his study showed no difference in vascularity between proliferative and non-proliferative benign lesion, but found a significant increase in vascularity in proliferative lesion from post-menopausal women.

Breast cancer is the leading cause of cancer deaths among women. Results from experimental studies suggest that tumour progression and metastasis in breast cancer is angiogenesis dependent. ${ }^{17,18}$

Angiogenesis has gained importance as a prognostic indicator in tumour progression. Tumour angiogenesis is generally measured by quantifying microvessel density in sections immunostained for vascular endothelial cell markers, such as CD34. Takao Kato et al ${ }^{19}$ found this marker to be a significant independent prognostic factor associated with longterm survival in Japanese breast cancer patients, especially in node-negative patients.

In the present study, predominant tumours were histologically grade II (46.60\%), followed by grade III $(33.40 \%)$ and grade I (20\%). A study by Dalton LW et $\mathrm{al}^{20}$ and Emad A Rakha et al ${ }^{21}$ showed majority of tumours were histologically grade II followed by grade I and grade III tumours.

In this study, high grade of microvessel density was seen among grade III tumours followed by grade II and grade I tumours. In the present study, a significant correlation ( $p$ value $<0.05$ ) was noted between histological grade and grade of microvessel density, similar to that found by Horak et al, 22 Weidner et al,23 and Bosari et al. ${ }^{24}$ However, Goulding et al,25 Marinho A et $\mathrm{al}^{26}$ failed to find any association between microvessel density and prognosis. 


\section{CONCLUSION}

Statistically significant severe microvessel density was seen in fibrocystic disease with epithelial hyperplasia. This shows that significant increase in angiogenesis occurs early, as ductal cells become hyperplastic.

Grade II and Grade III breast carcinoma showed high microvessel density when compared to grade I tumours. This correlation of microvessel density with tumour grade was statistically significant.

Therefore, assessment of angiogenesis may be helpful in selecting patients who would benefit from anti-angiogenic therapy.

\section{REFERENCES}

[1] Chen JH, Nalcioglu O, Su MY. Fibrocystic change of the breast presenting as a focal lesion mimicking breast cancer in MR Imaging. J Magn Reson Imaging 2008;28(6):1499-505.

[2] Bhardwaj JR, Prabaldeb. Boyd's Text book of Pathology. $10^{\text {th }}$ edn. India: Wolters Kluwer Health 2013:1240-2.

[3] McDivitt RW, Stevens JA, Lee NC, et al. Histologic types of benign breast disease and the risk for breast cancer. Cancer 1992;69(6):1408-14.

[4] Lester SC. The breast. Robbins and Cotran pathologic basis of disease. South Asia edn. India: Reed Elsevier India Private Limited 2014:p. 1051.

[5] Weidner N, Folkman J, Pozza F, et al. Tumor angiogenesis: a new significant and independent prognostic indicator in early-stage breast carcinoma. J Natl Cancer Inst 1992;84(24):1875-87.

[6] Inda AM, Andrini LB, Garcia MN, et al. Evaluation of angiogenesis with the expression of VEGF and CD34 in human non-small cell lung cancer. J Exp Clin Cancer Res 2007;26(3):375-8.

[7] Siitonen SM, Haapasalo HK, Rantala IS, et al. Comparison of different immunohistochemical methods in the assessment of angiogenesis: lack of prognostic value in a group of 77 selected nodenegative breast carcinomas. Mod Pathol 1995;8(7):745-52.

[8] Hosseini M, Tizmaghz A, Otaghvar HA, et al. The prevalence of fibrocystic changes of breast tissue of patients who underwent reduction mammoplasty in Rasool-Akram, Firuzgar and Sadr Hospitals during 2007-2012. Advances in Surgical Sciences 2014;2(1):5-8.

[9] Talei A, Akrami M, Mokhtari M, et al. Surgical and Clinical Pathology of breast diseases. In: Martinez EP, ed. Histopathology - reviews and recent advances. Tech 2012.

[10] Page DL, Vander Zwaag R, Rogers LW, et al. Relation between component parts of fibrocystic disease complex and breast cancer. J Natl Cancer Inst 1978;61(4):1055-63.

[11] Dupont WD, Parl FF, Hartmann WH, et al. Breast cancer risk associated with proliferative breast disease and atypical hyperplasia. Cancer 1993;71(4):1258-65.
[12] Guray M, Sahin AA. Benign breast diseases: classification, diagnosis, and management. Oncologist 2006;11(5):435-49.

[13] Guinebretiere JM, Le Monique G, Gavoille A, et al. Angiogenesis and risk of breast cancer in women with fibrocystic disease. J Natl Cancer Inst 1994;86(8):6356.

[14] Bluff JE, Menakuru SR, Cross SS, et al. Angiogenesis is associated with the onset of hyperplasia in human ductal breast disease. British Journal of Cancer 2009;101(4):666-72.

[15] Viacava P, Naccarato AG, Bocci G, et al. Angiogenesis and VEGF expression in pre-invasive lesions of the human breast. J Pathol 2004;204(2):140-6.

[16] Fregene T, Kellogg CM, Pienta K. Microvessel and quantification as a measure of angiogenic activity in benign breast tissues lesions: a marker for precancerous disease? Int J Oncol 1994;4(6):1199202.

[17] Carpenter PM, Chen WP, Mendez A, et al. Angiogenesis in the progression of breast ductal proliferations. Int J Surg Pathol 2011;19(3):335-41.

[18] Heffelfinger SC, Yassin R, Miller MA, et al. Vascularity of proliferative breast disease and carcinoma in situ correlates with histological features. Clin Cancer Res 1996;2(11):1873-8.

[19] Kato T, Kameoka S, Kimura T, et al. Angiogenesis as a predictor of long-term survival for 377 Japanese patients with breast cancer. Breast Cancer Research and Treatment 2001;70(1):65-74.

[20] Dalton LW, Page DL, Dupont WD. Histologic grading of breast carcinoma. A reproducibility study. Cancer 1994;73(11):2765-70.

[21] Rakha EA, El-Sayed ME, Lee AH, et al. Prognostic significance of Nottingham histologic grade in invasive breast carcinoma. J Clin Oncol 2008;26(19):3153-8.

[22] Horak ER, Leek R, Klenk N, et al. Angiogenesis, assessed by platelet/endothelial cell adhesion molecule antibodies, as indicator of node metastases and survival in breast cancer. Lancet 1992;340(8828):1120-4.

[23] Weidner N. Intratumor microvessel density as a prognostic factor in cancer. Am J Pathol 1995;147(1):9-19.

[24] Bosari S, Lee AK, DeLellis RA, et al. Microvessel quantitation and prognosis in invasive breast carcinoma. Hum Pathol 1992;23(7):755-61.

[25] Goulding H, Abdul Rashid NF, Robertson JF, et al. Assessment of angiogenesis in breast carcinoma: an important factor in prognosis. Hum Pathol 1995;26(11):1196-200.

[26] Marinho A, Soares R, Ferro J, et al. Angiogenesis in breast cancer is related to age but not to other prognostic parameters. Pathology Research and Practice 1997;193(4):267-73. 